\title{
TITLE:
}

\section{Estimation of gas and liquid slug lengths for T-shaped microreactors}

$\operatorname{AUTHOR}(S)$ :

Miyabayashi, K.; Tonomura, O.; Hasebe, S.

\section{CITATION:}

Miyabayashi, K.... [et al]. Estimation of gas and liquid slug lengths for Tshaped microreactors. Chemical Engineering Journal 2015, 262: 11371143

ISSUE DATE:

2015-02-15

URL:

http://hdl.handle.net/2433/192768

\section{RIGHT:}

C 2014 Elsevier B.V.; この論文は出版社版でありません。引用の際には 出版社版をご確認ご利用ください。; This is not the published version. Please cite only the published version. 
Estimation of Gas and Liquid Slug Lengths for T-shaped Microreactors

K. Miyabayashi, O. Tonomura*, S. Hasebe

Process Control \& Process Systems Engineering Laboratory

Department of Chemical Engineering

Kyoto University

A4- 120, Katsura Campus, Nishikyo, Kyoto, 615-8510, Japan

Tel: +81-(0)75-383-2637

Fax: +81-(0)75-383-2657

http://www-pse.cheme.kyoto-u.ac.jp/index-e.htm

*Email: tonomura@cheme.kyoto-u.ac.jp

\begin{abstract}
Microreactors with gas-liquid slug flow have an advantage over the conventional batch reactors in mass transfer between mutually immiscible fluids because of the internal circulation flow
\end{abstract}


within the liquid slug. To realize stable long-term operation of microreactors with gas-liquid slug flow, the slug lengths in the microreactors have to be monitored and controlled, because they influence mass transfer performance. In this study, an experimental investigation is carried out to analyze the formation of gas-liquid slug flow in a T-shaped microreactor. The experimental result shows that the pressures in gas and liquid feeding tubes connected to the microreactor oscillate periodically along the formation of a pair of gas and liquid slugs. Based on this result, a method for estimating slug lengths from feed pressure measurements is developed. The method is non-invasive and does not affect slug formation or the manner of gas-liquid slug flow. Its effectiveness was assessed through experimental case studies using T-shaped microreactors having different gas-liquid confluence angles and different gas and liquid flow rates. The relative root mean square errors of estimated slug lengths were within $2 \%$ for one minute operation. The results clearly show that the proposed method can be applied to the real time monitoring of slug lengths.

Keywords: Microreactor; Gas-liquid slug flow; Slug length estimation; Process monitoring 


\section{Introduction}

Microreactors with micro/millimeter wide tubes or channels can realize short residence time as

well as high mass and heat transfer rates. Recently, microreactors with multi-phase flow have attracted researchers' and engineers' attention by their unique flow characteristics. For example, when two mutually immiscible fluids, such as gas and liquid, are simultaneously fed into a microchannel, various flow patterns such as annular, dispersed and slug flows are generated as to the design and operating conditions [1]. Among these, slug flow, also called Taylor flow or segmented flow, is especially attractive for its small residence time distribution and large interface area per fluid volume [2]. In addition, rapid mass transfer between two phases is achieved because the liquid interface is constantly renewed by the circulation flow inside the liquid slug [3]. As the examples of applications of T-shaped microreactors with gas-liquid slug flow, Yasukawa et al. [4] reported that a space-time yield of the oxidation of ethyl lactate for producing ethyl pyruvate in microreactors was ten-times larger than that in conventional reactors. Takebayashi et al. [5] reported that the direct carbonylation of nitrobenzene to phenylisocynate was conducted by using T-shaped microreactors with gas-liquid slug flow, and the isocyanate yield in microreactor was three to six times higher than that in the batch reactor. 
In addition to the extensive basic research on microreactors with gas-liquid slug flow has been conducted, researches on the systematic design methods are important. For example, it is necessary to develop design and operation methods of mixers that can generate slug flows with desired slug lengths, because the slug length is one of the important state variables that affect mass transfer between two different phases [6]. Garstecki et al. [7] presented a quasi-static model for slug formation in a T-shaped micromixer, composed of rectangular microchannels and derived the scaling law for the estimation of slug length. According to Garstecki's law, the gas and liquid slug lengths formed in T-shaped micromixer are estimated by the following equations:

$$
L_{\mathrm{G}} / D=\beta+\alpha Q_{\mathrm{G}} / Q_{\mathrm{L}}
$$

where $L_{\mathrm{G}}$ is the gas slug length, $D$ is the equivalent inner diameter of the microchannel, and $Q_{\mathrm{G}}$ and $Q_{\mathrm{L}}$ are flow rates of gas and liquid fed into the T-shaped micromixer. $\alpha$ and $\beta$ are parameters that depend on the fluid properties, surface properties of the channels and the channel sizes. To predict the formed slug sizes, many researchers have presented models based on Garstecki's law and have determined $\alpha$ and $\beta$ by using computational fluid dynamics simulations or experiments for various mixing geometries and fluid properties $[8,9,10,11,12]$. By using the models based on Garstecki's law, the channel sizes are designed to generate slug flows with desirable slug lengths. 
The design of flow distributors that can achieve a uniform flow distribution among the parallelized microchannels is also important for large scale production, because non-uniformity in the flow distribution causes variation from the prescribed reaction time and results in a decrease in the product yield. Al-Rawashdeh et al. $[13,14]$ developed a gas-liquid reactor with modular flow distributors and parallelized channels. The reactor is made of steel and has an inspection window to visualize the slug flows. Matsuoka et al. [15] developed a stacked multi-channel reactor (SMCR $\left.{ }^{\circledR}\right)$, which is composed of stacked stainless steel plates with parallelized microchannels and flow distributors. SMCR ${ }^{\circledR}$ realizes the 3-dimentional parallelization of microchannels and can be applied to industrial-scale production. Both above-mentioned distributors have manifold structure. Yue et al. [16] developed a parallel microchannel contactor integrated with two constructal flow distributors. As a distributor, they adopted not the manifold structure but the dichotomous branching structure. To observe the flow condition, the contactor is made of transparent photosensitive epoxy resin.

In addition to the design methods for micromixers and flow distributors, a process monitoring method needs to be developed to realize stable long-term operation of microreactors, because abnormal conditions such as the deposition of solid on the surface of microchannels are likely to 
occur. Such disturbances affect the physical condition of the microchannels, and change the slug lengths to undesired values. Thus, for a long period operation, process monitoring systems that can detect such unacceptable condition are necessary. Optical methods $[17,18]$ and electrical methods [19] have been proposed as the measuring methods of void fraction in microchannels. Though these methods are applicable to the monitoring of slug lengths, there are some drawbacks. As the optical method requires the placement of the windows on the microchannels to visualize the slug flow, it is not applicable to microreactors made of opaque materials. The electrical method uses the electrical resistance and capacitance of fluid in the microchannels to estimate the condition in the channel. If the device is made of electrically-conductive materials such as stainless steel, complicated electrically-insulated placement of electrodes is required. Hence, the objective of this research is to develop alternatives to the conventional measuring methods of slug lengths in microchannels.

The outline of this paper is as follows: In Section 2, the relationship between the flow behavior and pressure changes of gas and liquid feeds is discussed through experimental observation on the gas-liquid slug flow generation in a T-MR. In Section 3, a new estimation method for slug lengths is proposed on the basis of the experimental results shown in Section 2, and the effectiveness of the developed estimation method is verified through several case studies. 


\section{Gas-liquid Slug Flow in T-shaped Microreactors}

In several numerical and experimental studies [20, 21, 22], it is reported that the feed pressure fluctuates according to the formation of slug flow. By considering this fact, in this research, the feed pressure measurements are used for slug length estimation. In this section, the characteristic points of feed pressure profiles that correspond to the formation of gas and liquid slugs in T-junction are made clear by using experimental data.

\subsection{Experimental Setup}

Figure 1 shows an experimental system used in this study. Pure nitrogen (gas) and distillated water (liquid) are fed into a T-shaped microreactor (T-MR) from a gas cylinder and a pressure tank, respectively. In this experiment, three types of micromixers shown in Figure 2 are used. The gas flow rate is controlled by a mass flow controller (FCST-1005LC, Fujikin). The liquid flow rate is controlled by a mass flow controller (LV-F50PO, HORIBA STEC). The control accuracy of both controllers is $\pm 1 \%$ of full scale $(10.0 \mathrm{~mL} / \mathrm{min})$. After gas and liquid are contacted in the micromixer, slug flow is formed and goes through a succeeding tube. The end of the tube is immersed in a beaker filled with water. The beaker is open to the atmosphere, and the water level of the beaker is kept constant. The sizes and materials of tubes and micromixers 
are summarized in Table 1. The length between the pressure sensor and the micromixer is defined as the length of feeding tube. The micromixers are made of polymethyl methacrylate (PMMA). The tubes (JR-T-6806-M10, VICI AG International) are made of fluorinated ethylene propylene (FEP). All of the channels and tubes have circular cross-sections. The temperature and pressure limits of the T-MR are $353 \mathrm{~K}, 7 \mathrm{kPaG}$.

The slug formation behavior in the micromixer is observed by high-speed video camera (VW-6000, KEYENCE) as shown in Figure 3, and the feed pressures of gas and liquid are measured by pressure sensors (PA-830-101G-10, NIDEC COPAL ELECTRONICS). The linearity of pressure sensor is $\pm 0.5 \%$ of rated pressure $(9.81 \mathrm{kPa})$. The minimum response time of the pressure sensor is 2 milliseconds. The pressure sensors are installed to gas and liquid feeding tubes through T-shaped adapter as shown in Figure 4. The digital fiber-optic sensor unit (FU-L51Z, KEYENCE) is installed at near the inlet of FEP tube. In the digital fiber-optic sensor unit, two neighboring optical probes are set along the flow direction at $4 \mathrm{~mm}$ interval. Using the signals from two optical probes placed a certain interval, the two signals can be cross-correlated to determine the time lag and then yield instantaneous superficial velocity of slug flow and slug lengths of gas and liquid [18]. According to the obtained superficial velocity, time-varying $Q_{\mathrm{G}}$ and $Q_{\mathrm{L}}$ are calculated. The threshold signal level for the digital fiber-optic sensor unit to 
distinguish gas or liquid phase is determined so that the average value of $Q_{\mathrm{L}}$ for a minute is equal to the set value of liquid mass flow controller. The measurements acquired from pressure sensors and digital fiber-optic sensor unit are collected in a computer through a data logger (NR-600, KEYENCE) at time intervals of 2 milliseconds, which is equal to the minimum response time of the pressure sensor. For each of three types of T-MRs, data are collected at almost steady state condition.

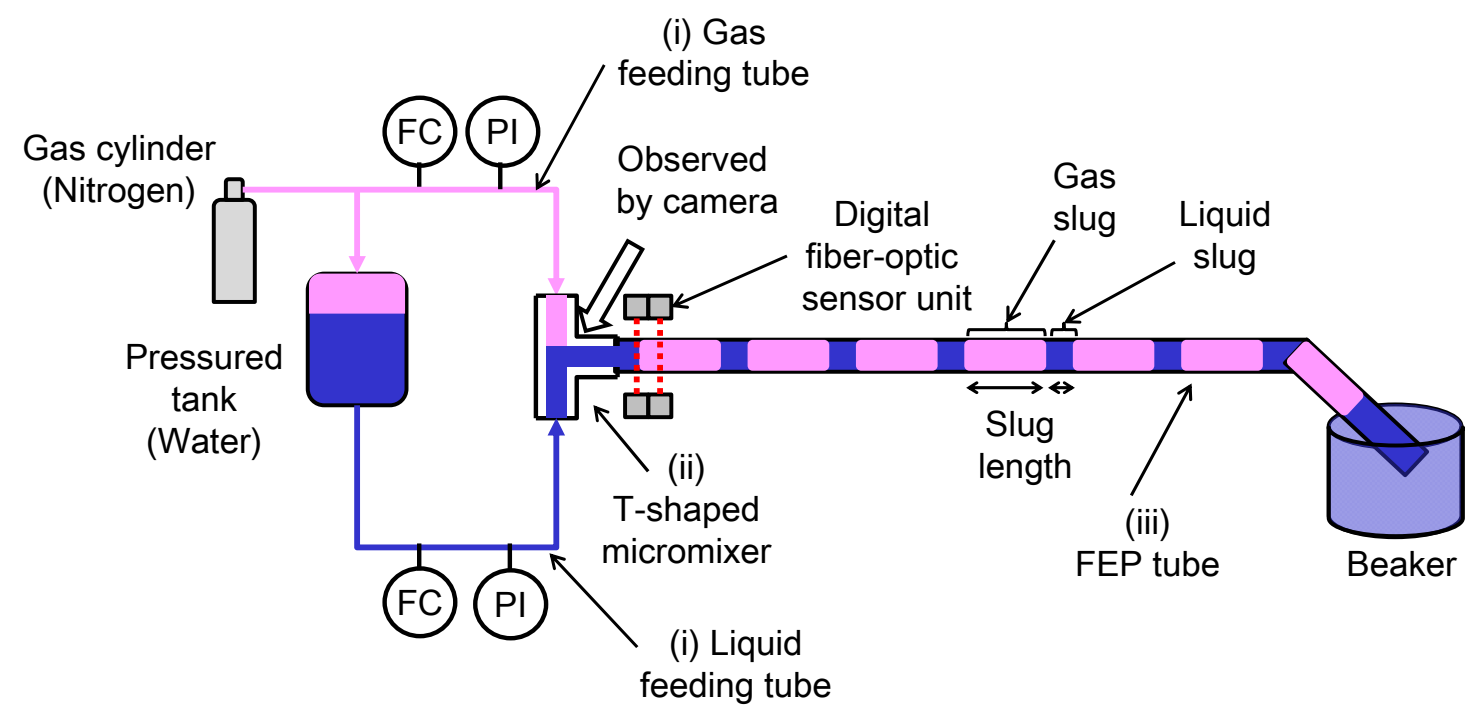

Figure 1. Experimental system of a single T-shaped microreactor 


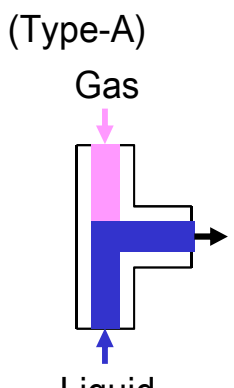

(Type-B)

(Type-C)

Liquid
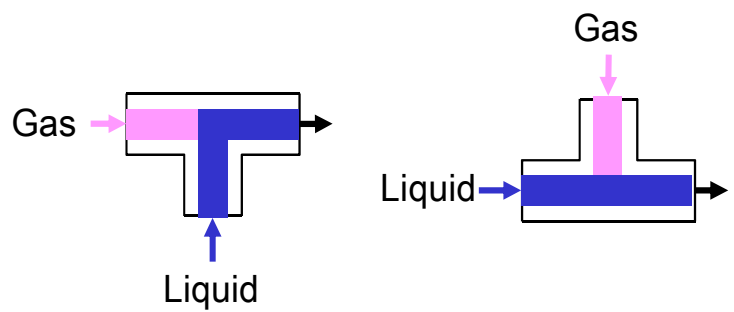

Figure 2. Schematic diagrams of three types of micromixers

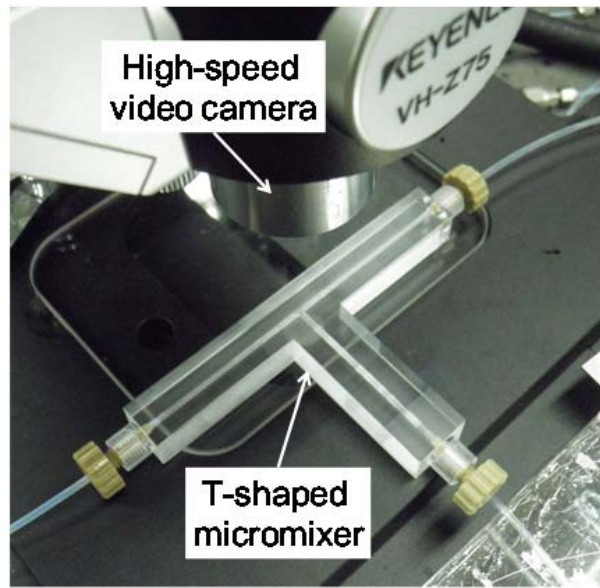

Figure 3. T-shaped micromixer observed by high-speed video camera

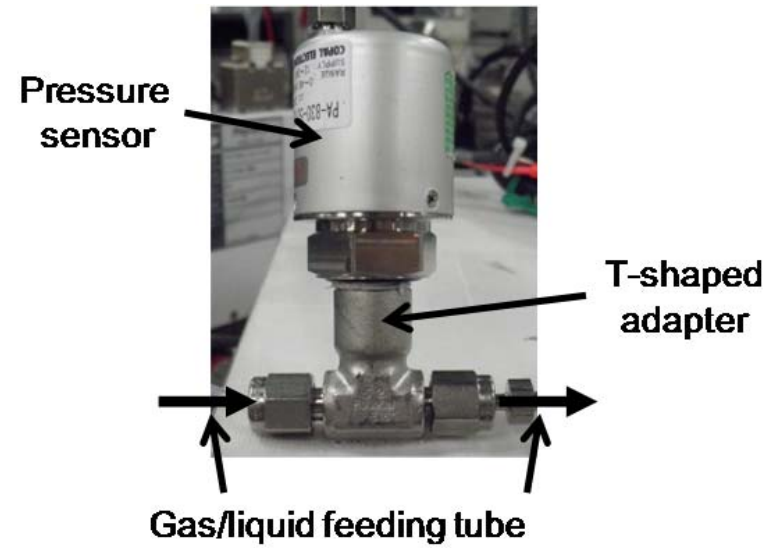

Figure 4. Pressure sensor installed to gas/liquid feeding tube 
Table 1. Sizes and materials of tubes and T-shaped microreactor

\begin{tabular}{cccc}
\hline Location in Fig. 1 & I.D. [mm] & Length [mm] & Material \\
\hline (i) Feeding tube & 1.00 & 100 & FEP \\
(ii) Micromixer & 1.30 & 40 for all branches & PMMA \\
(iii) Reactor tube & 1.00 & 500 & FEP \\
\hline
\end{tabular}

\subsection{Slug Formation and Pressure Oscillation}

The experimental results of T-MRs with three types of micromixers are explained in this subsection. Figure 5 shows a photo of gas-liquid slug flow in the Type-A mixer made of PMMA, and Figure 6 shows a photo of gas-liquid slug flow in the succedent tube made of FEP, where $Q_{\mathrm{G}}$ and $Q_{\mathrm{L}}$ are $1.0 \mathrm{~mL} / \mathrm{min}$. As shown in Figure 5, all of gas slugs in the PMMA mixer have hemispherical caps and cylindrical bodies. However, as shown in Figure 6, all of gas slugs in FEP tube have no liquid film [23], and the shapes are almost cylindrical. This is because FEP has hydrophobic property. Figure 6 shows that the pressures at gas and liquid feed flows of the T-MR with Type-A mixer. Both pressures oscillate periodically and the oscillation phases of gas and liquid pressures have a half cycle difference. For clearly observing the profile of gas and liquid pressure measurements, smoothed lines obtained by the Savitzky-Golay filter [24] are shown in black lines. 
Figure 8 shows the gas-liquid slug formation behavior in Type-A mixer. Photos in Figure 8 are taken at time $\mathrm{A}$ to time $\mathrm{E}$ in Figure 7 . The gas and liquid discharge alternately from the confluence part of the mixer into the succeeding tube. The relationship between the periodic pressure fluctuation and the formation of gas and liquid slugs is explained as follows: During the period between Figure 8A and just before Figure 8C, the gas penetrates to the confluence part of the mixer, but it is still blocked by liquid flow. Thus, the gas pressure continuously increases because gas is constantly supplied to the confluence part. At the time shown in Figure 8C, the gas occupies the confluence part, and the gas starts flowing from the confluence part to the succeeding tube. By the flow, the pressure of the gas feeding section gradually decreases. The flow behavior of liquid during the periods from Figure $8 \mathrm{C}$ to $8 \mathrm{E}$ is explained in a similar manner as that of gas during the periods from Figure 8A to 8C. These phenomena are repeated as far as gas-liquid slugs are formed. 


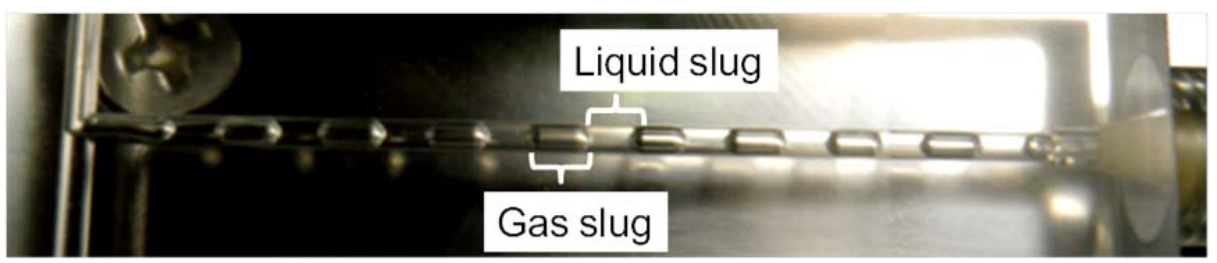

Figure 5. Photo of gas-liquid slug flow in the PMMA mixer

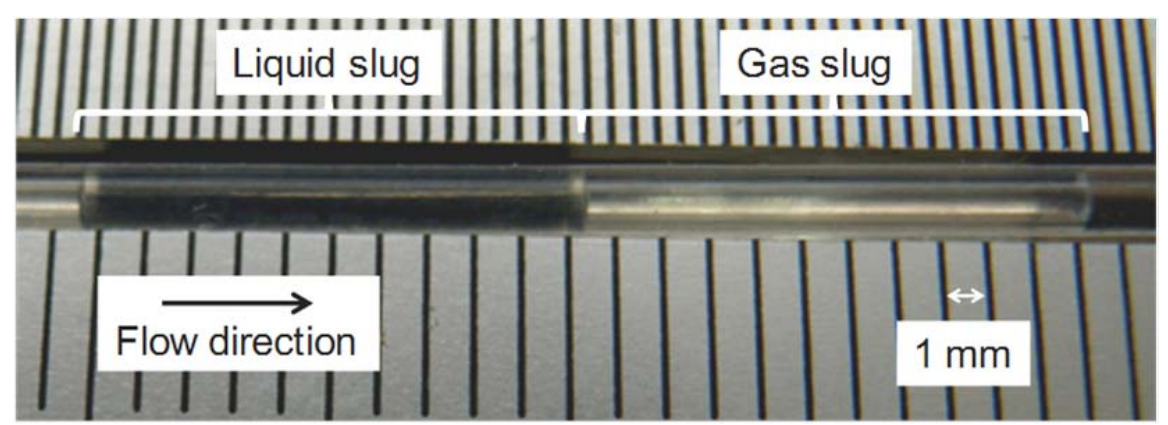

Figure 6. Photo of gas-liquid slug flow in the FEP tube

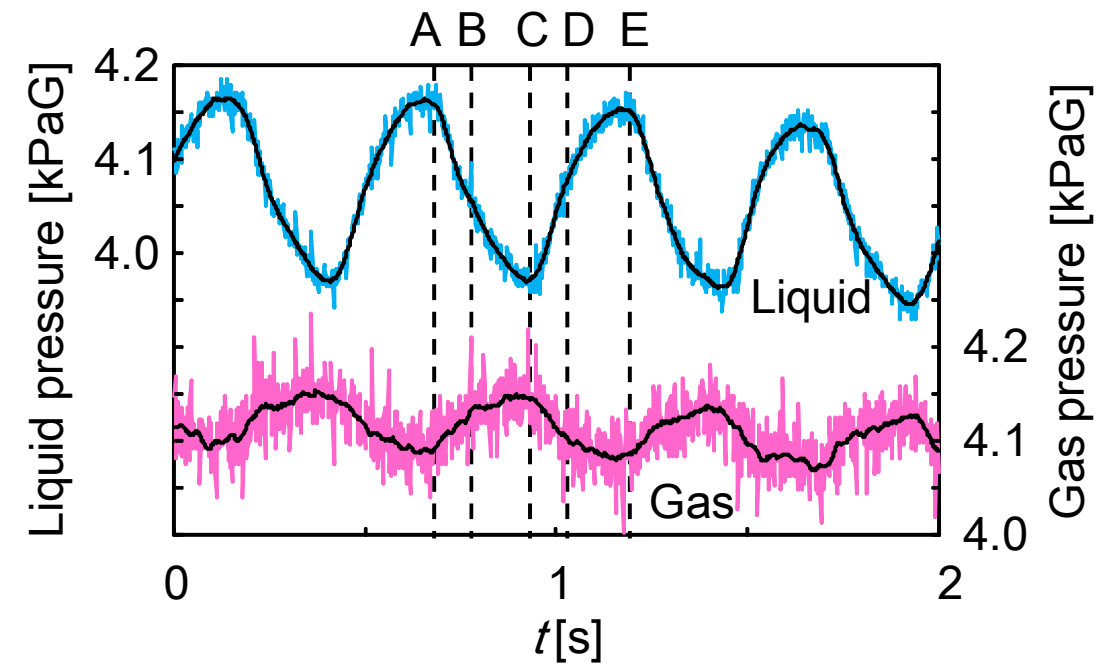

Figure 7. Profiles of gas and liquid pressure changes: $Q_{\mathrm{G}}=Q_{\mathrm{L}}=1.0 \mathrm{~mL} / \mathrm{min}$, Type-A mixer 

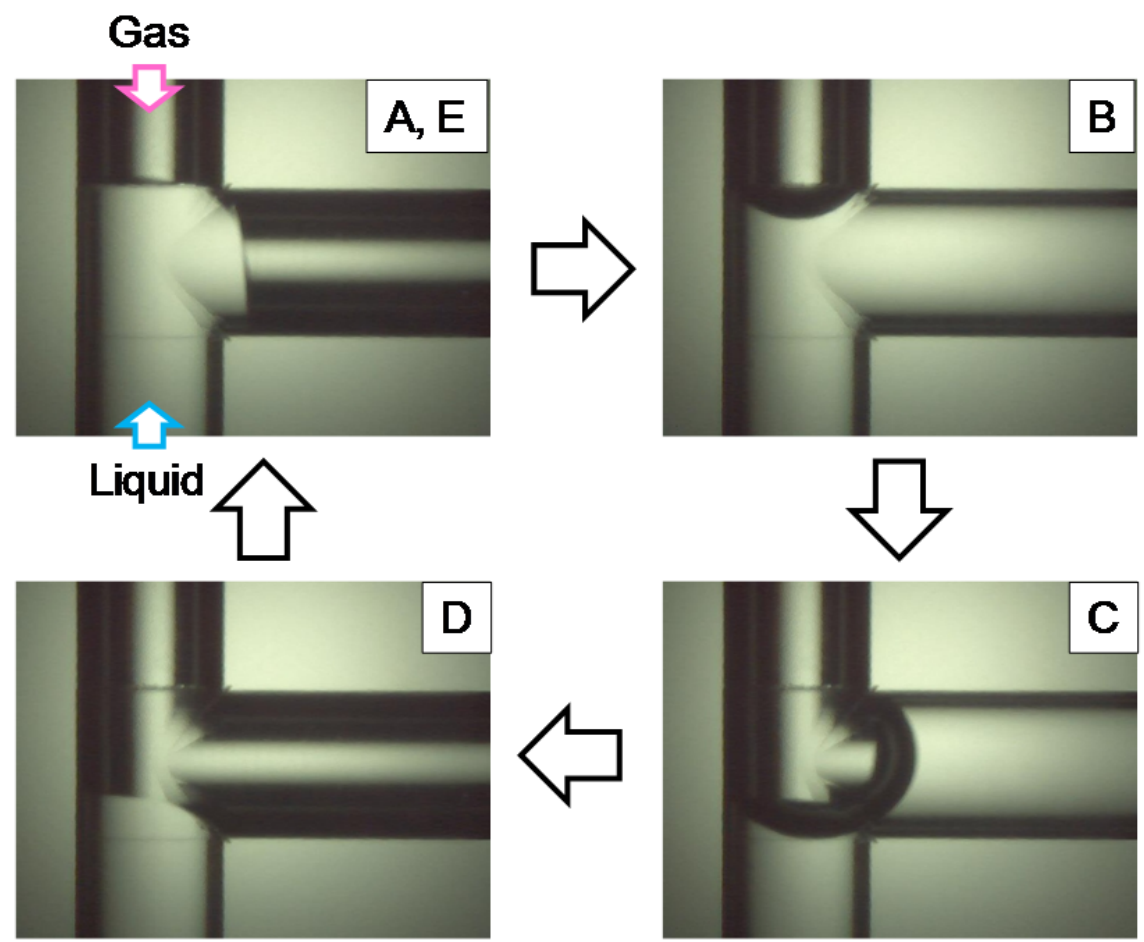

Figure 8. Photos of flow behavior in Type-A mixer
A, E: Liquid blocks gas flow and starts flowing to the succeeding tube.
$\mathrm{B}$ : Liquid flows to the succeeding tube, and gas is penetrating to the confluence part.
C: Gas blocks liquid flow and starts flowing to the succeeding tube.
D: Gas flows to the succeeding tube, and liquid is penetrating to the confluence part.

Figures 9 and 11 show the pressure profiles of gas and liquid feed flows for Type-B and Type-C mixers, respectively, and Figures 10 and 12 show the gas-liquid slug formation behavior in Type-B and Type-C mixers, respectively. As shown in Figures 9 to 12, the gas and liquid pressures oscillate periodically, and gas and liquid slugs are generated in the same manner as the experimental results of Type-A mixer. The measured pressure profiles in three type mixers are almost same as the profiles reported in previous studies [20, 21, 22]. In all experiments, the 
magnitude of liquid pressure oscillation is larger than that of gas pressure oscillation, and the profile of liquid pressure change is clearer than that of gas pressure change. This is due to the difference of the fluid properties between gas and liquid, such as viscosity, compressibility and wettability. Thus, the liquid pressure profile is used in the slug length estimation explained in the next section.

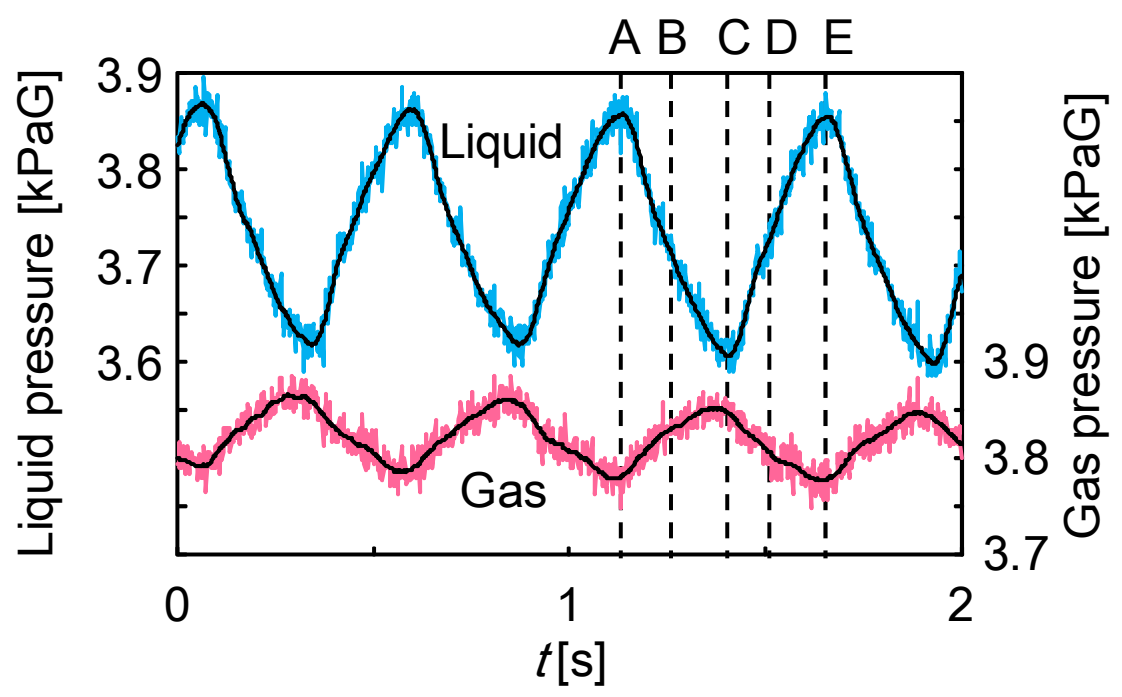

Figure 9. Profiles of gas and liquid pressure changes: $Q_{\mathrm{G}}=Q_{\mathrm{L}}=1.0 \mathrm{~mL} / \mathrm{min}$, Type-B mixer 


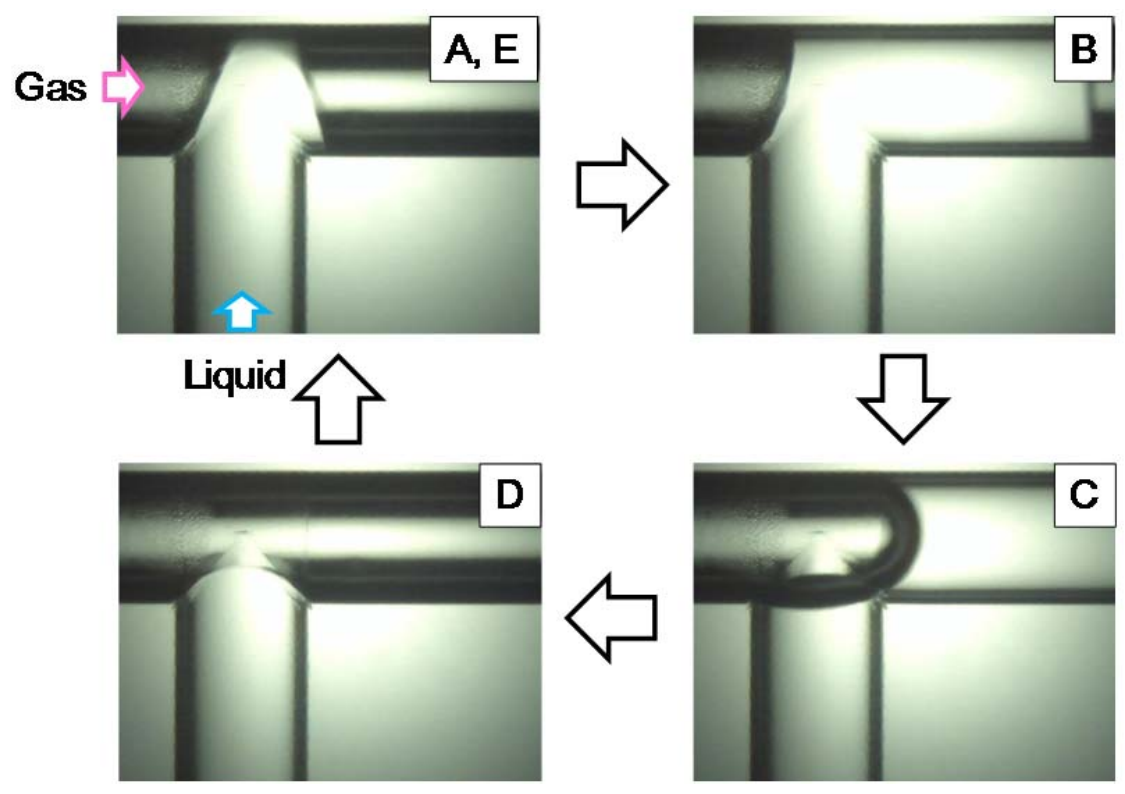

Figure 10. Photos of flow behavior in Type-B mixer

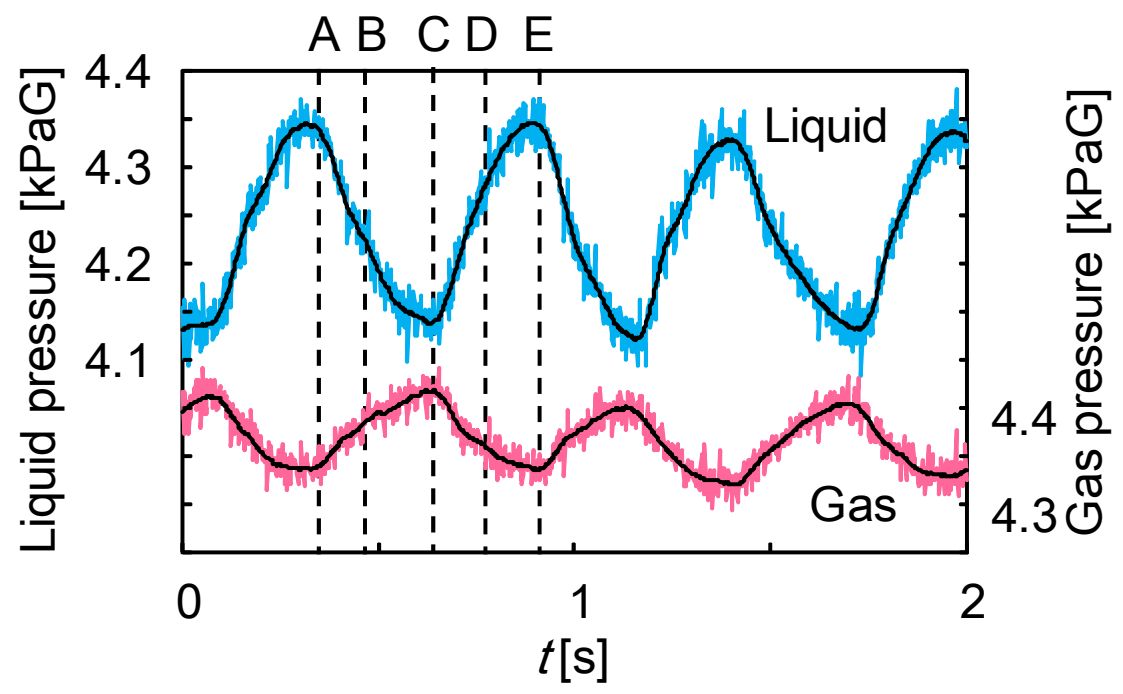

Figure 11 Profiles of gas and liquid pressure changes: $Q_{\mathrm{G}}=Q_{\mathrm{L}}=1.0 \mathrm{~mL} / \mathrm{min}$, Type-C mixer 


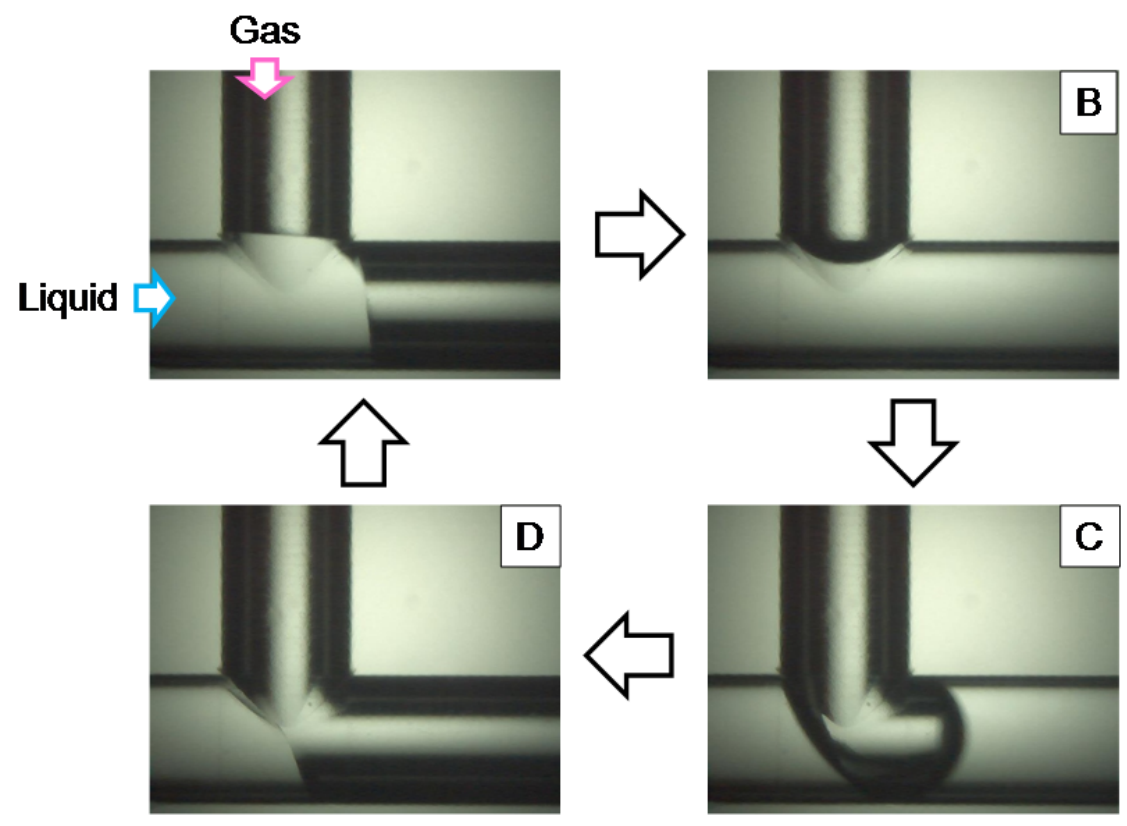

Figure 12. Photos of flow behavior in Type-C mixer

\section{Slug Length Estimation}

An estimation method of slug lengths is proposed in this section, and the effectiveness of the proposed method is verified through several case studies for the T-MR. Because the experimental results of T-MRs with Type-B and C are very similar to those of T-MR with Type-A, the experimental results of T-MR with Type-A are only shown in this section.

\subsection{Estimation Method of Slug Lengths}

In Section 2, it was explained that the pressure of liquid feed flow increases during the period when the gas flows from the confluence part to the succeeding tube, and it decreases during the 
period when the liquid flows from the confluence part to the succeeding tube. Thus, the time from the peak of the periodic liquid pressure oscillation to the bottom of it is defined as the gas flow period, and is expressed by $t_{\mathrm{G}}$. Similarly, the time from the bottom of the periodic liquid pressure oscillation to the next peak is defined as the liquid flow period, and is expressed by $t_{\mathrm{L}}$. In this research, it is assumed that the cross section area of the succeeding tube to the mixer is constant and no liquid films exist in the tube. Under such condition, slug lengths can be estimated by following equations:

$$
\begin{aligned}
& L_{\mathrm{G}}^{*}=\left(Q_{\mathrm{G}}+Q_{\mathrm{L}}\right) t_{\mathrm{G}} / A \\
& L_{\mathrm{L}}^{*}=\left(Q_{\mathrm{G}}+Q_{\mathrm{L}}\right) t_{\mathrm{L}} / A
\end{aligned}
$$

where $A$ is cross sectional area of the succeeding tube to the mixer, $L_{\mathrm{G}}^{*}$ and $L_{\mathrm{L}}^{*}$ are estimated values of gas slug length $L_{\mathrm{G}}$ and liquid slug length $L_{\mathrm{L}}$, respectively. From Eqs. (2) and (3), the gas and liquid slug lengths can be estimated by using the feed pressure of gas or liquid and the flow rates of gas and liquid.

\subsection{Verification of Developed Estimation Method}

For three cases explained in Table 2, accuracy of the proposed estimation method is evaluated.

The pressure measurements of gas and liquid feed flows for Cases 2 and 3 are shown in Figures

13 and 14, respectively. For clearly observing the profile of gas and liquid pressure 
measurements, smoothed lines obtained by the Savitzky-Golay filter [24] are shown in black lines. For Case 1, the pressure measurements are same as those in Figure 7 of Section 2.2.

For each case, one minute data of $L_{\mathrm{G}}$ and $L_{\mathrm{L}}$ are collected by digital fiber-optic sensor unit. Because the pressure at the installed point of the digital fiber-optic sensor unit is higher than the atmospheric pressure due to the pressure drop of slug flow in FEP tube, the gas slugs are compressed and their lengths are shorter than those at the atmospheric pressure. Therefore, the $L_{\mathrm{G}}$ are adjusted to the values at the standard condition (273 K. $\left.101.3 \mathrm{kPa}\right)$ according to the gas state equation. At the same time, one minute data of $t_{\mathrm{G}}$ and $t_{\mathrm{L}}$ are extracted from the feed pressure data, and they are used to calculate $L_{\mathrm{G}}^{*}$ and $L_{\mathrm{L}}^{*}$ by Eqs. (2) and (3). The results are summarized in Figure 15. The average values of measured and estimated gas slug lengths, $\bar{L}_{\mathrm{G}}$ and $\bar{L}_{\mathrm{G}}^{*}$, and those of measured and estimated liquid slug lengths, $\bar{L}_{\mathrm{L}}$ and $\bar{L}_{\mathrm{L}}^{*}$ are shown in Table 3. In addition, the relative root mean square error for $L_{\mathrm{G}}^{*}$ and $L_{\mathrm{L}}^{*}\left(\mathrm{RRMSE}_{\mathrm{G}}, \mathrm{RRMSE}_{\mathrm{L}}\right)$ calculated according to Eq. (4) and (5) are also shown in Table 3:

$$
\operatorname{RRMSE}_{\mathrm{G}}(\%)=\frac{1}{\bar{L}_{\mathrm{G}}} \sqrt{\frac{\sum_{i}\left(L_{\mathrm{G}, i}^{*}-L_{\mathrm{G}, i}\right)}{N}} \times 100
$$




$$
\operatorname{RRMSE}_{\mathrm{L}}(\%)=\frac{1}{\bar{L}_{\mathrm{L}}} \sqrt{\frac{\sum_{i}\left(L_{\mathrm{L}, i}^{*}-L_{\mathrm{L}, i}\right)}{N}} \times 100
$$

where $N$ is the number of data (50 data). From the material balance of feeding gas and liquid, the following relationships must be satisfied:

$$
Q_{\mathrm{G}} / Q_{\mathrm{L}}=\bar{L}_{\mathrm{G}} / \bar{L}_{\mathrm{L}}=\bar{L}_{\mathrm{G}}^{*} / \bar{L}_{\mathrm{L}}^{*}
$$

The values in Eq. (6) are also shown in Table 3. As shown in Table 3, it is confirmed that $Q_{\mathrm{G}} / Q_{\mathrm{L}}, \bar{L}_{\mathrm{G}} / \bar{L}_{\mathrm{L}}$ and $\bar{L}_{\mathrm{G}}^{*} / \bar{L}_{\mathrm{L}}^{*}$ take almost the same values for each case. And the RRMSE $\mathrm{G}_{\mathrm{G}}$ and $\mathrm{RMSE}_{\mathrm{L}}$ are within $2 \%$ in all cases. It means that slug lengths can be estimated accurately by using the proposed estimation method. When Eq. (4) is satisfied, slug lengths can be calculated from $t_{\mathrm{G}}, t_{\mathrm{L}}$ and either of gas or liquid flow rate, $Q_{\mathrm{G}}$ or $Q_{\mathrm{L}}$.

Even if $Q_{\mathrm{G}}$ and $Q_{\mathrm{L}}$ are constant, the length of individual slug fluctuates during the operation. Figures 16 to 18 show the estimates and measurements of five successive gas and liquid slug lengths in Cases 1 to 3 . These data were selected from the periods in which the fluctuations of slug lengths are relatively large. From Figures 16 to 18 and Table 3, it is confirmed that $L_{\mathrm{G}}$ and $L_{\mathrm{L}}$ in all cases are estimated accurately by using the proposed estimation method.

In general, as $Q_{\mathrm{G}}$ and $Q_{\mathrm{L}}$ become larger, the frequency of slug formation becomes greater and 
the $t_{\mathrm{G}}$ and $t_{\mathrm{L}}$ become shorter. Therefore, if the minimum response time of pressure sensor $\left(t_{\mathrm{R}}\right)$ is not sufficiently-shorter than the $t_{\mathrm{G}}$ and $t_{\mathrm{L}}$, the developed estimation method is not applicable.

Considering that $L_{\mathrm{G}}^{*}$ in Eq. (2) is equal to $L_{\mathrm{G}}$, and by substituting the Eq. (2) into Eq. (1), the following equation is obtained:

$$
t_{\mathrm{G}}=\frac{D}{A} \frac{\left\{\beta+\alpha\left(Q_{\mathrm{G}} / Q_{\mathrm{L}}\right)\right\}}{\left(Q_{\mathrm{G}}+Q_{\mathrm{L}}\right)}
$$

By comparing $t_{\mathrm{R}}$ and $t_{\mathrm{G}}$ derived by Eq. (7), the applicable upper limits of $Q_{\mathrm{G}}$ and $Q_{\mathrm{L}}$ for the developed estimation method are determined. Assuming that $Q_{\mathrm{G}} / Q_{\mathrm{L}}=1, t_{\mathrm{R}}$ is 2 milliseconds and the tenth part of $t_{\mathrm{R}}$ is necessary to obtain $t_{\mathrm{G}}$ from pressure data, the applicable upper limit of $Q_{\mathrm{G}}$ (= $Q_{\mathrm{L}}$ ) is determined as $12.3 \mathrm{~mL} / \mathrm{min}$ according to Eq. (7), where $\alpha$ and $\beta$ are considered to be constant with flow rates and calculated as 3.79 and 4.27 based on the experimental results in Cases 1 to 3. 


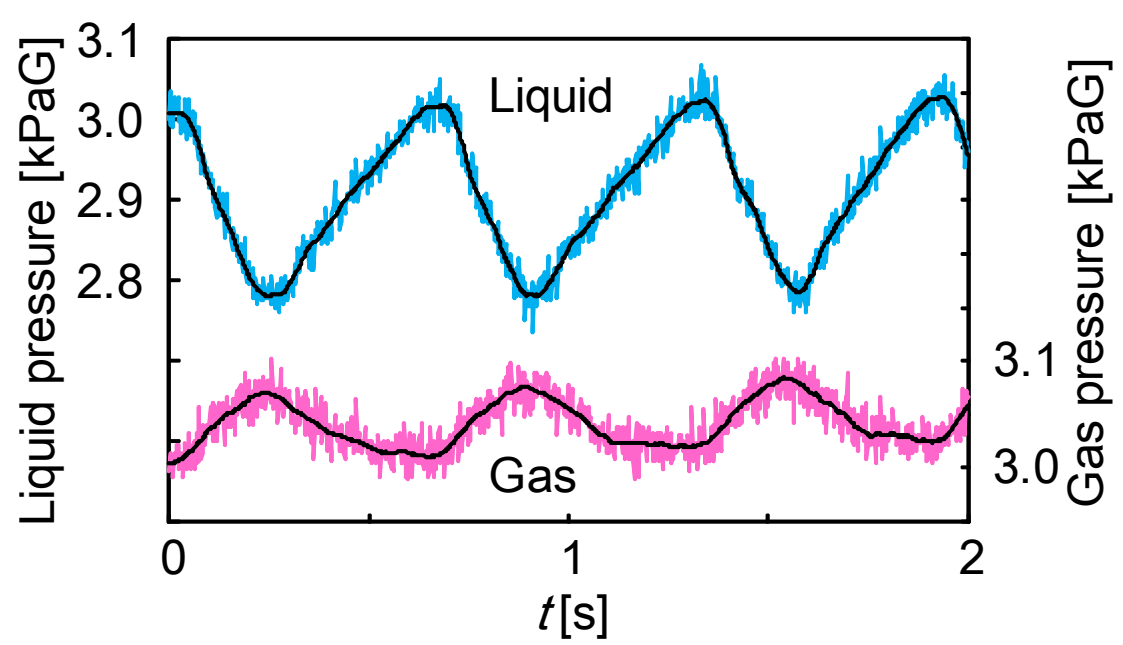

Figure 13. Profiles of gas and liquid pressure changes:

Case 2: $Q_{\mathrm{G}}=1.0 \mathrm{~mL} / \mathrm{min}, Q_{\mathrm{L}}=0.5 \mathrm{~mL} / \mathrm{min}$ Type-A mixer

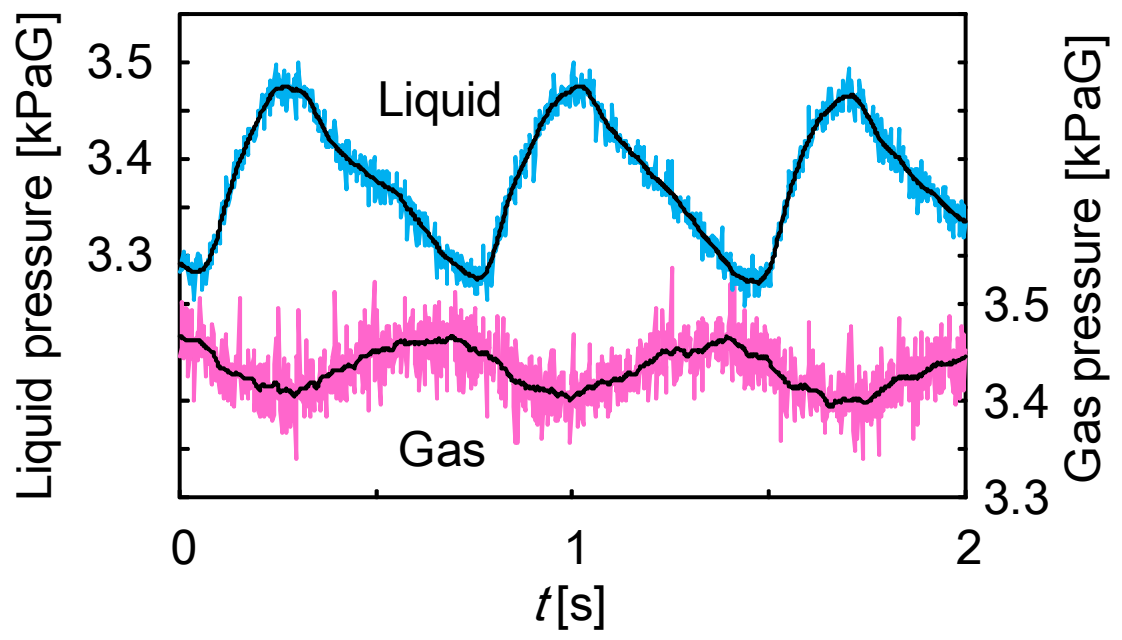

Figure 14. Profiles of gas and liquid pressure changes:

Case 3: $Q_{\mathrm{G}}=0.5 \mathrm{~mL} / \mathrm{min}, Q_{\mathrm{L}}=1.0 \mathrm{~mL} / \mathrm{min}$ Type-A mixer 


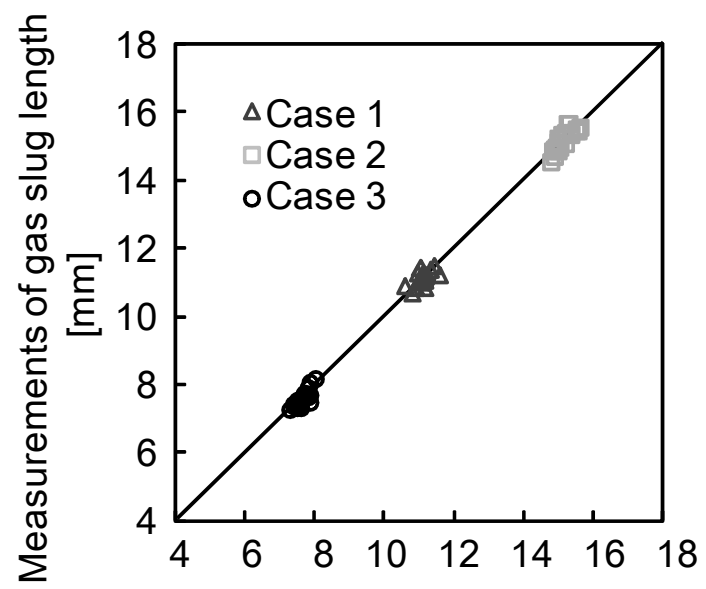

Estimates of gas slug length [mm]

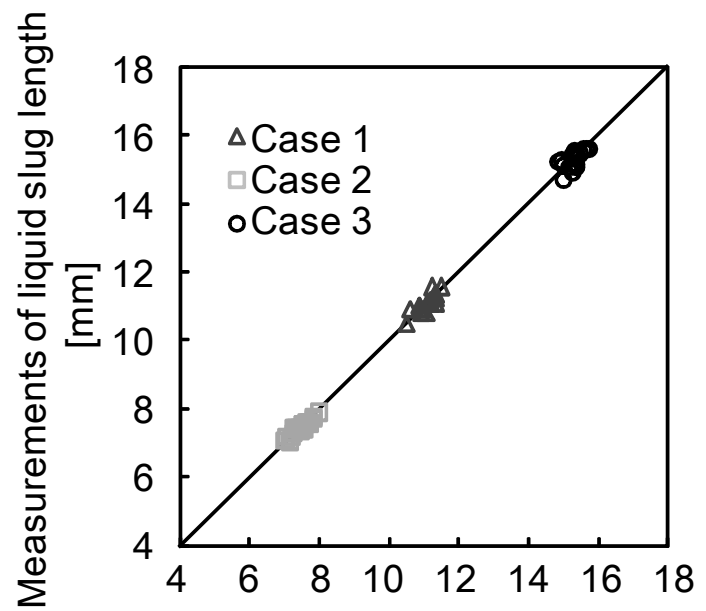

Estimates of liquid slug length [mm]

Figure 15. Estimates and measurements of gas and liquid slug lengths

Table 3. Estimates and measurements of gas and liquid slug lengths

\begin{tabular}{cccccccc}
\hline & $Q_{\mathrm{G}} / \mathrm{Q}_{\mathrm{L}}$ & $\begin{array}{c}\bar{L}_{\mathrm{G}}^{*}: \bar{L}_{\mathrm{G}} \\
{[\mathrm{mm}]}\end{array}$ & $\begin{array}{c}\text { RRMSE }_{\mathrm{G}} \\
{[\%]}\end{array}$ & $\begin{array}{c}\bar{L}_{\mathrm{L}}^{*}: \bar{L}_{\mathrm{L}} \\
{[\mathrm{mm}]}\end{array}$ & $\begin{array}{c}\text { RRMSE }_{\mathrm{L}} \\
{[\%]}\end{array}$ & $\bar{L}_{\mathrm{G}} / \bar{L}_{\mathrm{L}}$ & $\bar{L}_{\mathrm{G}}^{*} / \bar{L}_{\mathrm{L}}^{*}$ \\
\hline Case 1 & 1.0 & $11.1: 11.0$ & 1.8 & $11.1: 11.1$ & 1.8 & 1.00 & 0.99 \\
Case 2 & 2.0 & $15.2: 15.3$ & 1.4 & $7.6: 7.6$ & 1.5 & 2.00 & 2.01 \\
Case 3 & 0.5 & $7.6: 7.5$ & 1.9 & $15.1: 15.2$ & 2.0 & 0.50 & 0.49 \\
\hline
\end{tabular}
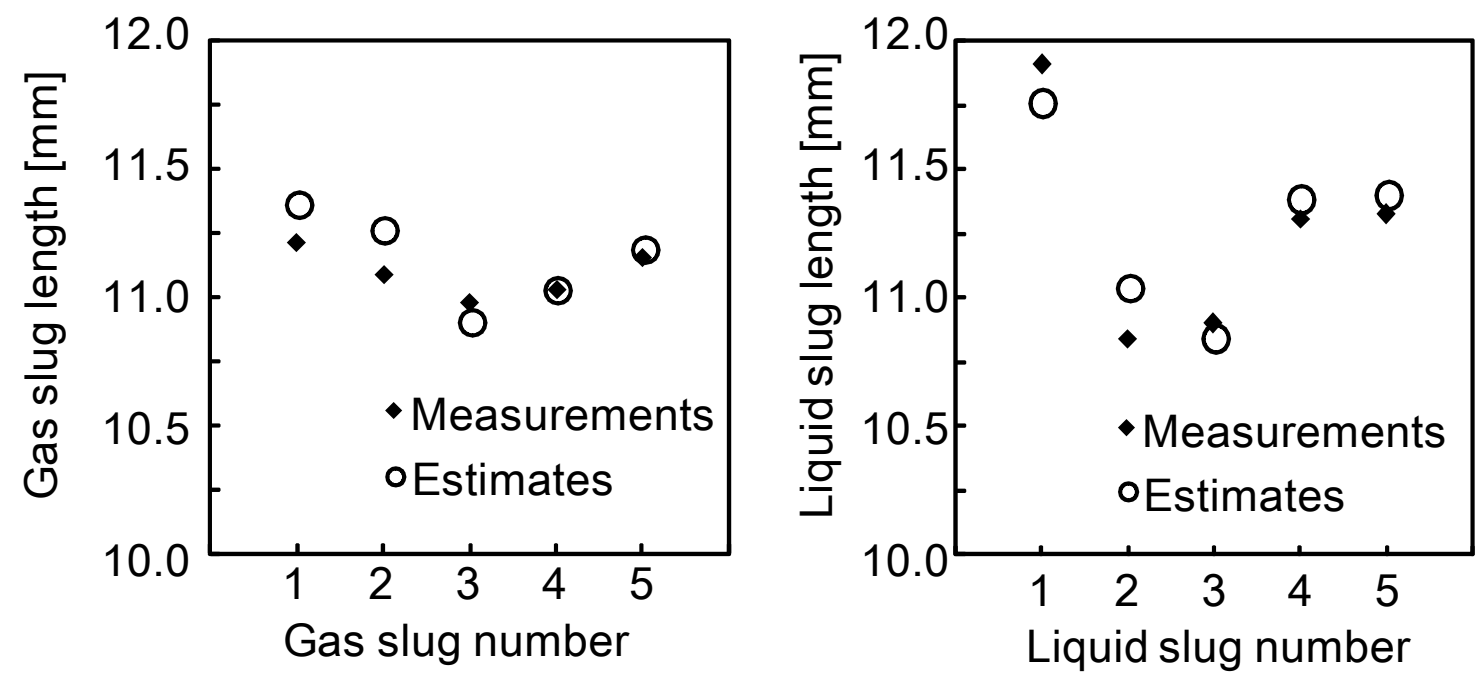

Figure 16. Successive estimation of gas and liquid slug lengths for Case 1 

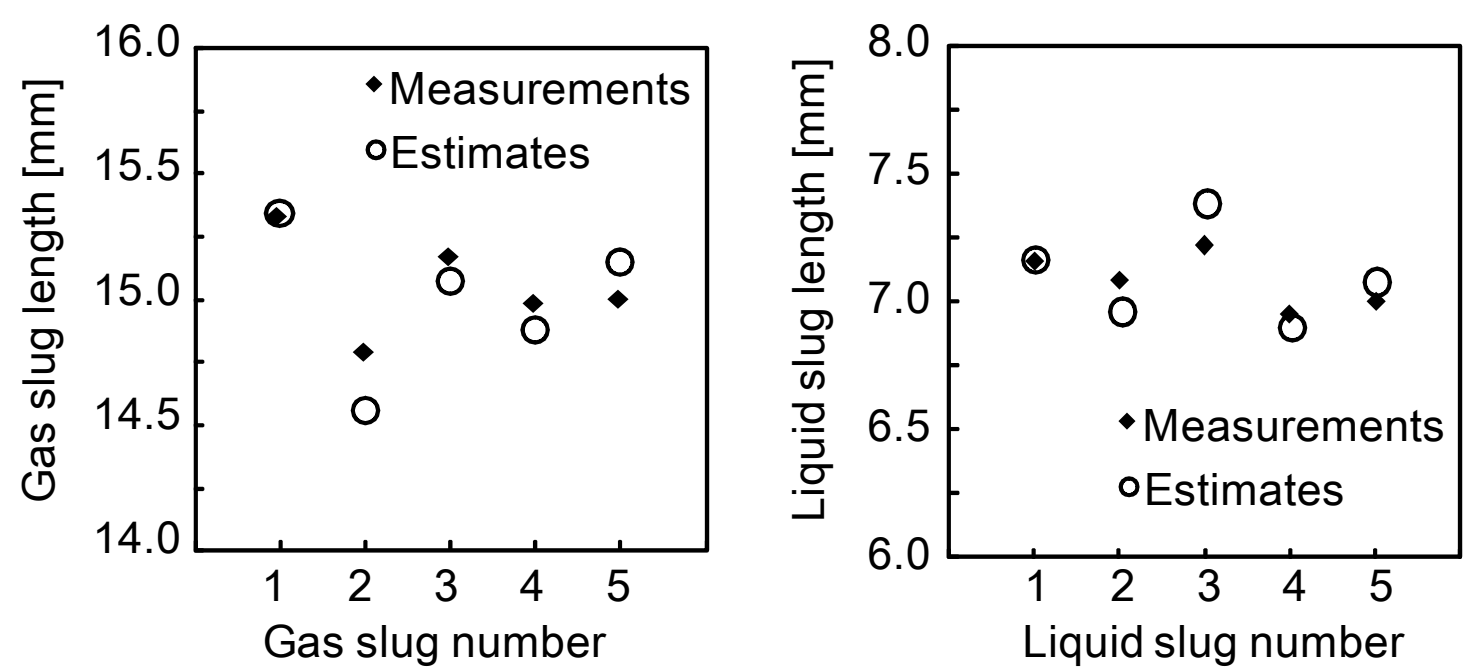

Figure 17. Successive estimation of gas and liquid slug lengths for Case 2
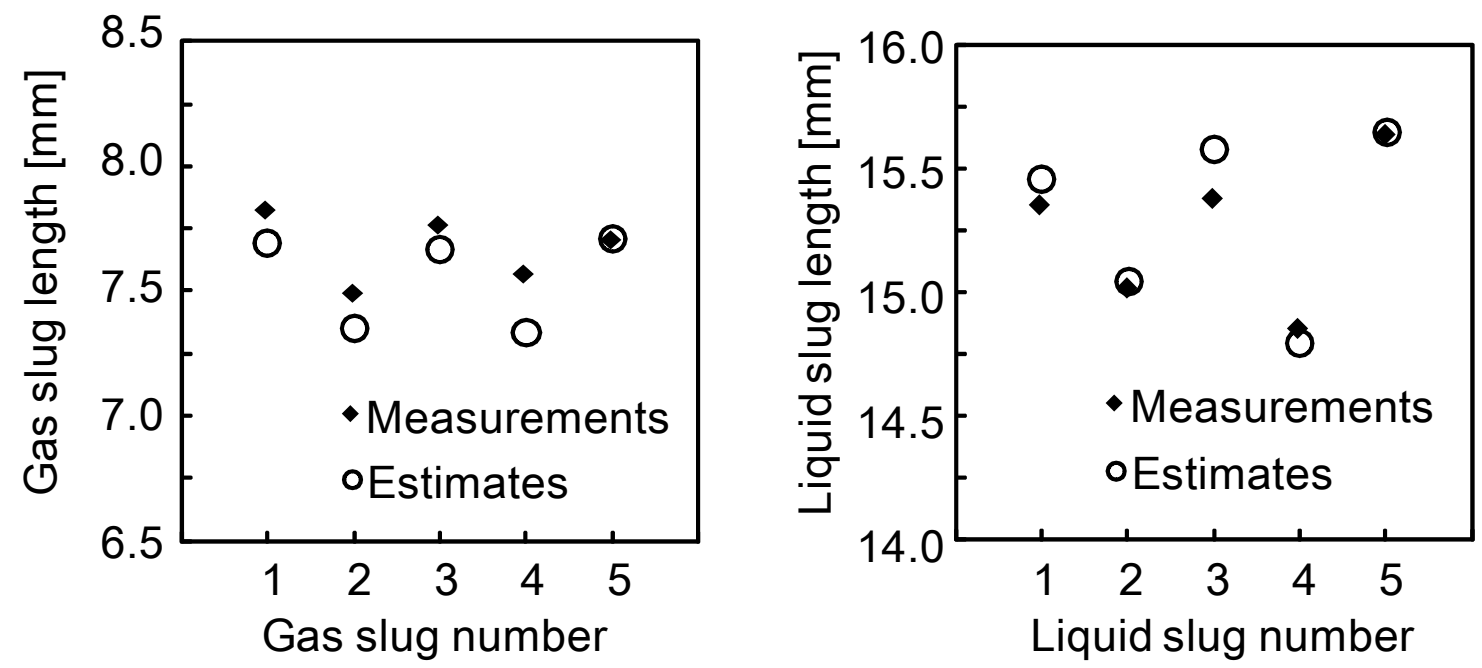

Figure 18. Successive estimation of gas and liquid slug lengths for Case 3

\section{Conclusion}

In microreactors with gas-liquid slug flow, the slug lengths are important design variables, 
because they influence the mass transfer performance. In this study, from the precise experimental investigation of T-shaped microreactor, it was made clear that the pressures in gas and liquid feeding tubes oscillate periodically along the formation of a pair of gas and liquid slugs. By using this fact, an estimation method of slug lengths from the measurements of feed pressure of gas or liquid was developed, whose effectiveness was verified through several case studies of T-shaped microreactors. By this method, the slug lengths can be monitored without complicated processing, such as the placement of the windows and electrodes on microchannels. In this study, a monitoring method of slug length in single channel microreactor was discussed. The next target is to expand the proposed method to multi-channel microreactors with slug flow.

\section{References}

[1] N. Shao, A. Gavriilidis, P. Angeli, Flow regimes for adiabatic gas-liquid flow in microchannels, Chemical Engineering Science 64 (2009) 2749-2761

[2] M. T. Kreutzer, A. Gunther, K. F. Jensen, Sample dispersion for segmented flow in microchannels with rectangular cross section, Analytical Chemistry 805 (2008) 1558-1567

[3] M. N. Kashid, I. Gerlach, S. Goetz, J. Franzke, J. F. Acker, F. Platte, D. W. Agar, S. Turek, Internal circulation within the liquid slugs of a liquid-liquid slug-flows capillary microreactor, Industrial \& Engineering Chemistry Research 44 (2005) 5003-5010. 
[4] T. Yasukawa, W. Ninomiya, K. Ooyachi, N. Aoki, K. Mae, Enhanced production of ethyl pyruvate using gas-liquid slug flow in microchannel, Chemical Engineering Journal 167 (2011) $527-530$

[5] Y. Takebayashi, K. Sue, S. Yoda, T. Furuya, K. Mae, Direct carbonylation of nitrobenzene to phenylisocyanate using gas-liquid slug flow in microchannel, Chemical Engineering Journal 180 (2012) 250-254

[6] N. Aoki, S. Tanigawa, K. Mae, A new index for precise design and advanced operation of mass transfer in slug flow, Chemical Engineering Journal 167 (2011) 651-656

[7] P. Garstecki, M. J. Fuerstman, H. A. Stone, G. M. Whitesides, Formation of droplets and bubbles in a microfluidic T-junction - scaling and mechanism of break-up, Lab on a Chip 6 (2006) 437-446

[8] V. van Steijn, M. T. Kreutzer, C. R. Kleijn, $\mu$-PIV study of the formation of segmented flow in microfluidic T-junctions, Chemical Engineering Science 62 (2007) 7505-7514

[9] J. Tan, S.W. Li, K. Wang, G.S. Luo, Gas-liquid flow in T-junction microfluidic devices with a new perpendicular rupturing flow route, Chemical Engineering Journal 146 (2009) 428-433 [10] A. Leclerc, R. Philippe, V. Houzelot, D. Schweich, C. Bellefon, Gas-liquid Taylor flow in square micro-channels: New inlet geometries and interfacial area tuning, Chemical Engineering Journal 165 (2010) 290-300 
[11] V. van Steijn, C. R. Kleijn, M. T. Kreutzer, Predictive model for the size of bubbles and droplets created in microfluidic T-junctions, Lab on a Chip 10 (2010) 2513-2518

[12] T. Abadie, J. Aubin, D. Legendre, C. Xuereb, Hydrodynamics of gas-liquid Taylor flow in rectangular microchannels, Microfluid Nanofluid 12 (2012) 355-369

[13] M. Al-Rawashdeh., X. Nijhuis, E. V. Rebrov, V. Hessel, J. C. Schouten, Design methodology for barrier-based two phase flow distributor, AIChE Journal 58 (2012) 11 3482-3493

[14] M. Al-Rawashdeh., F. Yu, T. A. Nijhuis, E. V. Rebrov, V. Hessel, J. C. Schouten, Numbered-up gas-liquid micro/milli channels reactor with modular flow distributor, Chemical Engineering Journal 207-208 (2012) 645-655

[15] A. Matsuoka, D. Nishikawa, T. Yamashita, K. Noishiki, Effect of immiscible fluid injection to liquid flow on mixing performance in microchannel reactor, 12th International Conference on Microreaction Technology (2012) T3-P-15

[16] J. Yue, R. Boichot, L. Luo, Y. Gonthier, G. Chen, Q. Yuan, Flow distribution and mass transfer in a parallel microchannel contactor integrated with constructal distributors, AIChE Journal 562 (2010) 298-317

[17] N. Nguyen, S. Lassemono, F. A. Chollet, Optical detection for droplet size control in microfluidic droplet-based analysis systems, Sensors and Actuators B: Chemical 117212 
(2006) 431-436

[18] H. Ide, R. Kimura, M. Kawaji, Optical measurement of void fraction and bubble size distributions in a microchannel, Heat Transfer Engineering 28 (2009) 713-719.

[19] J. Ye, L. Peng, W. Wang, W. Zhou, Optimization of helical capacitance sensor for void fraction measurement of gas-liquid two-phase flow in a small diameter tube, IEEE Sensors Journal 1110 (2011) 2189-2196

[20] M. De Menech, P. Garstecki, F. Jousse, H. A. Stone, Transition from squeezing to dripping in a microfluidic T-shaped junction, Journal of Fluid Mechanics 595 (2008) 141-161

[21] A. R. Abate, P. Mary, V. van Steijn, D. A. Weitz, Experimental validation of plugging during drop formation in a T-junction, Lab on a Chip 12 (2012) 1516-1521

[22] A. Riaud, C. P. Tostado, K. Wang, G. Luo, A facile pressure drop measurement system and its applications to gas-liquid microflows, Microfluid Nanofluid 15 (2013) 715-724

[23] G. I. Taylor, Deposition of a viscous fluid on the wall of a tube, Journal of Fluid Mechanics 10 (1961) 1161-1165

[24] A. Savitzky, M. J. E. Golay, Smoothing and differentiation of data by simplified least squares procedures, Analytical Chemistry 368 (1964) 1627-1639 